\section{Fruktose im Urin}

W. G. Guder

München, Deutschland

Synonym(e) Fruktosurie

Englischer Begriff fructose in urine

Definition $>$ Fruktose.

Struktur D-arabino-2-hexulose (s. Abbildung im Beitrag $>$ Fruktose).

Molmasse $180,16 \mathrm{~g}$.

Funktion - Pathophysiologie Angeborene Störungen des Fruktosestoffwechsels (reduzierte Metabolisierung und/oder tubuläre Resorption) können zur Ausscheidung von Fruktose im Urin führen.

Analytik $>$ Hochleistungs-Flüssigkeitschromatographie oder enzymatisch mit Sorbitoldehydrogenase. Die Methode mit Hexokinase setzt Elimination von \ Glukose voraus.

Referenzbereich - Erwachsene Unterhalb $0,3 \mathrm{mmol} / \mathrm{L}$ $(<60 \mathrm{mg} / 24 \mathrm{~h})$.

Referenzbereich - Kinder Unterhalb $0,3 \mathrm{mmol} / \mathrm{L}$ $(<60 \mathrm{mg} / 24 \mathrm{~h})$.
Indikation Historisch wird bei positivem unspezifischen Nachweis von Hexosen im Urin (mit Teststreifen für Glukose), aber fehlender Glukose der Verdacht auf andere Hexosen geweckt.

Da die Fruktoseintolerenz durch klinische Symptome bei der Einnahme von Früchten und anderen fruktosehaltigen Nahrungsmitteln (Honig, Rohrzucker) auffällt (Erbrechen, Hypoglykämie, Krämpfe bis zum Koma), wird meist die Diagnose durch Nachweis der Fruktose im Urin möglich sein. Defizienz der Fruktose-1-Phosphataldolase wird in Leber oder Darmgewebe nachgewiesen.

Interpretation Der Nachweis von Fruktose im Urin ( $\triangleright$ Seliwanoff-Test) spricht nur in Gegenwart von deutlichen klinischen Symptomen für angeborene Fruktoseintoleranz. Ansonsten kann Fruktose durch hohe Dosen oraler Zufuhr (Honig, „diabetische“ Süßigkeiten, Infusionen) oder Kontamination mit Seminalflüssigkeit (enthält $>8,3 \mathrm{mmol} / \mathrm{L}$ $(>50 \mathrm{mg} / \mathrm{dL})$ Fruktose!) im Urin nachweisbar sein.

\section{Literatur}

Schleicher E (2009) Fructose. In: Guder WG, Nolte J (Hrsg) Das Laborbuch in Klinik und Praxis, 2. Aufl. Elsevier/Urban und Fisher, München, S 764

Soldin SJ, Rifai N, Hicks JMB (1995) Biochemical basis of pediatric disease, 2. Aufl. AACC Press, Washington, DC 